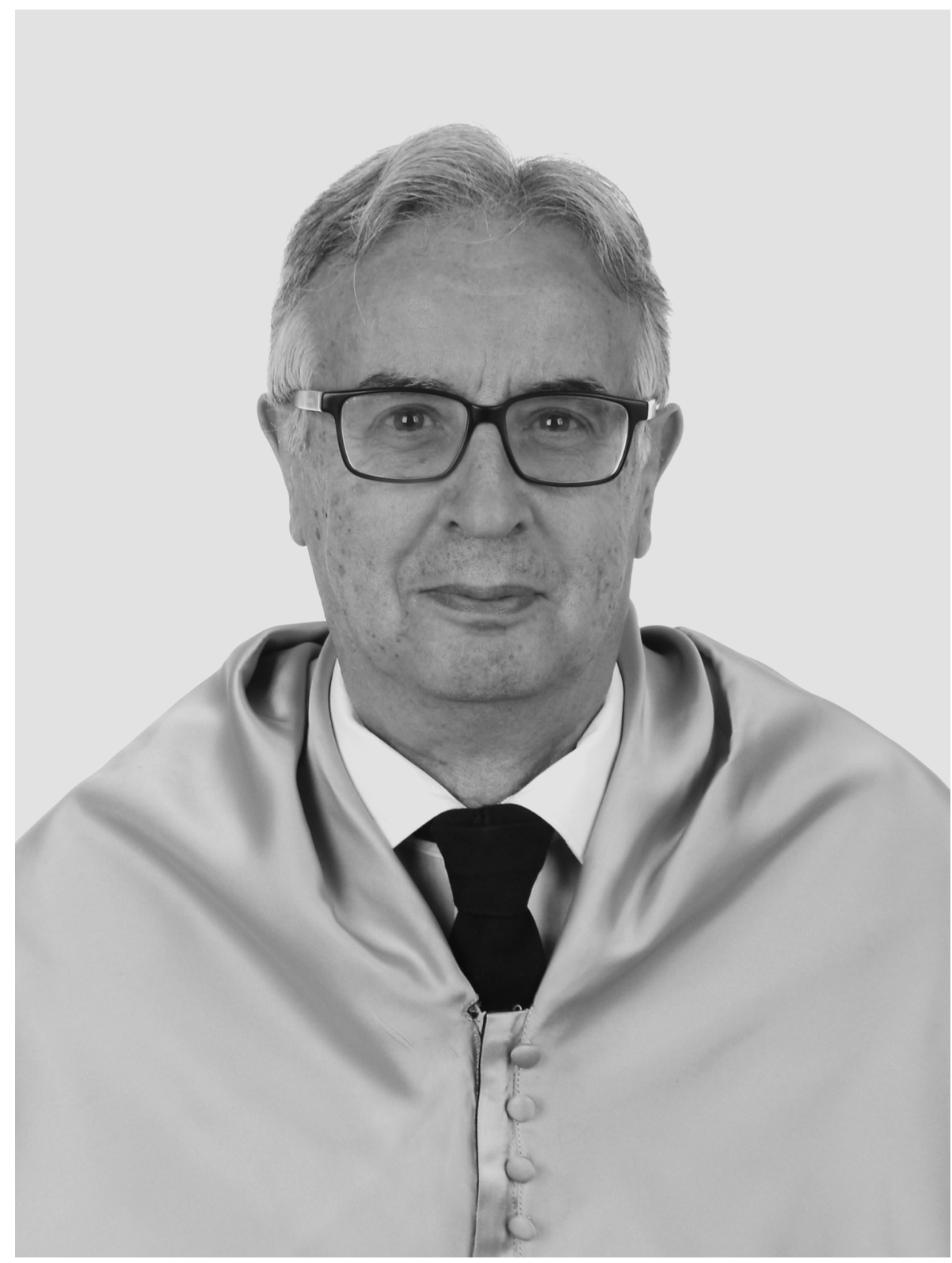




\title{
LA PASIÓN POR EL ESTUDIO. LAUDATIO ACADÉMICA DEL PROFESOR TELESFORO-MARCIAL HERNÁNDEZ SEMPERE
}

\author{
Carmen García Monerris \\ Universitat de València
}

Illma. Sra. Decana, señores doctores, amigos y compañeros: me dirijo a todos ustedes y de manera muy especial al profesor Telesforo Hernández con ocasión de su Laudatio, motivo de gran alegría para él y los que le acompañamos, y ocasión para poder repasar lo fundamental de su trayectoria docente e investigadora en esta Universidad, pero también expresión inevitable de una añoranza y, por qué no, de cierta tristeza, al tratarse de un acto de despedida de un compañero. Sin embargo, como dijo alguien, la añoranza, lejos de quedar prendida del pasado, tiene que dejar también abiertas las puertas a ciertas esperanzas de futuro.

Particularmente me encuentro en una situación paradójica. No puedo hablar en nombre de ningún Departamento: ni del de Historia Contemporánea porque el profesor homenajeado no perteneció a él, aunque tal vez debió pertenecer; ni del de Historia Moderna porque yo no estoy en él, aunque posiblemente debería estarlo. Tengo la impresión, tanto en su caso como en el mío, que padecemos una cierta desubicación, una cierta sensación de haber habitado durante mucho tiempo en los márgenes de épocas históricas e incluso de disciplinas diversas. Sin embargo, es esto mismo lo que me permite, tal vez, si no hablar oficialmente en nombre de nadie, sí hacerlo en el de muchas personas. Además, he de confesar públicamente mi gran satisfacción por ser yo la que se encargue de un acto de laudatio y despedida, en este caso de un gran amigo, de un fiel amigo, más allá de su condición y trayectoria académicas.

Desde muy joven, Telesforo Hernández tuvo ocasión de practicar en las imponentes escalinatas del no menos impresionante Instituto "Jorge Juan" de Alicante eso que hoy en día los modernos denominan "Parkour". El régimen parecía en ese momento seguro, puesto que, como él mismo me confesó, nunca tuvo que cantar el "Cara al Sol", mientras que yo sí que lo hice posteriormente, al izar y arriar la bandera, al comienzo y al final de la semana. Todo final de régimen comporta, parece evidente, mayores riesgos. Al acabar, sus pasos no se dirigieron hacia la universidad, sino hacia otra institución mítica en esa capital en aquellos momentos como era la fábrica "Manufacturas Metálicas Madrileñas", la popularmente conocida como "Las tres M". Telesforo, en efecto, conoció de primera mano y en su propia persona, una realidad social percibida a un tiempo como de explotación y de falta de libertad. Precisamente por eso, desde esa condición, decidió (y esto sí que fue totalmente voluntario) que debía seguir estudiando mientras trabajaba. Y se hizo maestro, un título que casi siempre ha ocultado pero que en su caso aúna las resonancias de tan loable profesión con la expresión manifiesta de los estudios como arma de lucha y de ascenso social. El trampolín hacia la universidad de Telesforo Hernández no fue ningún título ni ninguna prueba de acceso, en sentido estricto, sino esa firme voluntad de seguir trascendiendo una situación como mínimo incómoda. 
La universidad valenciana del tardo franquismo, a finales de los años 60 y primeros de los 70, concretamente la antigua Facultad de Filosofía y Letras (sección de Historia) en la que Telesforo se formó, presentaba, frente a la predominante mediocridad del resto, un elenco increíble de profesionales empeñados en la reconstrucción de una nueva Historia en un nuevo marco académico e institucional. Reglá, Jover Giralt, Tarradell, Ubieto, López Gómez, Rosselló..., son sólo algunos de los nombres que dirigieron la universidad, la historia o la geografía valencianas hacia los derroteros y por los caminos que todavía hoy en día son perceptibles. El "I Congreso de Historia del País Valenciano", celebrado en abril de 1971 (y en el que el entonces estudiante Telesforo Hernández participó) fue, como sabemos, el precipitado de un diseño de amplísimos vuelos, pero también el punto de arranque de una prometedora renovación. Muchas veces me he imaginado -he necesitado imaginármelo para sobrevivir- cómo podía ser aquel ambiente y aquellos años, cómo tras ambiciosos proyectos y líneas de investigación se iba trazando el andamiaje de una Historia cuyo objetivo fundamental y básico era pensar y construir un nuevo País. Y he necesitado imaginármelo para soportar en otros ambientes, casi por los mismos años e, incluso, unos años después, el insoportable hedor de una historia imperial y oficial, sólo reconocible en las hazañas del emperador Carlos V y en aquellos que, frente a la herejía siempre acechante de la razón y de la Ilustración, se empeñaban valerosamente en mantener a España en sus carriles de esencialidad religiosa y política, siendo impensable la una sin la otra.

Telesforo H. tuvo la suerte de aprender de todos ellos, especialmente de Joan Reglá, ya no sólo a ir manejándose en una nueva Historia, sino sobre todo a sentirla como un instrumento privilegiado de ciudadanía y de construcción de País. No en vano, en el arranque de la renovación pedagógica que significó el Colegio Oficial de Doctores y Licenciados de Valencia estuvo presente nuestro homenajeado, participando activamente en la organización, entre 1976 y 1983, de la irrepetible Escola d'Estiu del País Valencià. Y en esos momentos, hablar de Escola d'Estiu no era cualquier cosa: era hablar de gente y profesores como Manuel Tuñón de Lara, Josep Fontana, Albert Balcells o Juan José Carreras, por citar sólo unos pocos nombres. Con similar espíritu, su reiterada participación en los denominados Coloquios de Pau, en torno a la todopoderosa figura de Manuel Tuñón de Lara $(1978,1980,1987,1988,1991,1992,1999,2000 \ldots)$, marca una continuada trayectoria de renovación historiográfica y de compromiso cívico y político desde la disciplina.

Acabada la Licenciatura en 1972, se graduó en septiembre de ese mismo año con un tema elegido de entre los muchos que Reglá tenía ya en marcha o sugeridos a sus discípulos. En este caso se trataba de El pronunciamiento progresista de 1844 en Alicante y Cartagena, un trabajo inédito hasta el momento, del que su autor es consciente de muchas de sus limitaciones, pero que a comienzos de los 70 debió constituir, sin lugar a dudas, una novedad en la, en ese momento, casi desconocida trayectoria del diecinueve valenciano. No creo en las determinaciones, ni mucho menos: soy un ejemplo de haber empezado por el estudio de los gremios en Madrid y haber acabado con la Albufera de Valencia y la cultura constitucional del primer liberalismo. Pero en lo que sí que creo es en la progresiva delimitación de preferencias de ámbitos o problemas históricos sobre los que proyectamos y construimos nuestras contribuciones académicas y personales, porque no existen aquellas sin éstas. No es momento de adentrarse en motivaciones que exceden a nuestras limitadas capacidades, pero la realidad es que Telesforo entró en el siglo XIX y decidió permanecer en él, como tendremos ocasión de ver un poco más adelante. 


\section{ACTIVIDAD DOCENTE}

A pesar de mostrar desde el principio un ámbito de preferencia temático y cronológico por el XIX español y valenciano en particular, toda la trayectoria del profesor Telesforo Hernández transcurrió en el área y en el ámbito de la Historia Moderna. No nos engañemos: el diseño de amplias líneas de investigación sobre las que reconstruir Historia y País no conocían en el caso de Reglá de fronteras demasiado convencionales que luego acabaron imponiéndose. Su prematura muerte, como sabemos, truncó muchos proyectos, pero las semillas estaban ya germinando. Tuvo tiempo todavía de sugerir a Telesforo que el tema de su Tesis Doctoral, Ferrocarriles y Capitalismo en el País Valenciano, fuera dirigido por el profesor Fontana, aunque, por razones prácticas, la dirección acabó recayendo en el Dr. Sebastián García Martínez a sugerencia de aquel.

En la universidad española es muy difícil, por no decir prácticamente inexistente, la relación inmediata o directa entre investigación y docencia. Todos o la gran mayoría de nosotros tenemos la impresión de habernos formado como profesores "todo terreno" en disciplinas que, sin dejar de pertenecer a nuestro ámbito o área de especialización, han abarcado la totalidad de temas imaginables e, incluso, de disciplinas diversas. No es algo que lo sienta como especialmente negativo. Con un poco de habilidad y, es cierto, con mucha dedicación y esfuerzo, se pueden llegar a descubrir aspectos, problemas, enfoques y sugerencias que no nos proporcionaría nuestra particular dedicación a un tema o línea de investigación en exclusiva. Una buena docencia, al menos a nivel universitario, exige casi convertir en objeto preferente, al menos de indagación bibliográfica, algunos aspectos y procesos históricos que en principio parecen muy alejados de nuestras líneas habituales de investigación.

Telesforo H. ha recorrido, como la mayoría de nosotros, casi todas las figuras profesorales existentes en ese momento en la universidad española: Ayudante de Facultad y Encargado de Curso (1972-1975); de nuevo Ayudante de Facultad, compaginado con su condición de Becario de Investigación (1975-1979); dos años más de Encargado de Curso, Agregado interino en el curso 1981-1982; Adjunto contratado del 1982 al 1985 y Profesor Titular desde ese año hasta 2011, fecha en la que accedió a Catedrático. Ha sido, como muchos o la mayoría de nosotros, un profesor "todo terreno" que ha sabido incorporar perfectamente a su actividad investigadora alguna de sus facetas como docentes. Me refiero de manera particular a su dedicación a aspectos de la ingeniería social y técnica del setecientos valenciano o a aquellos otros que tuvieron que ver en su momento con el famoso problema de la proto-industrialización, o los relativos al humanismo en la Ilustración española. Inevitablemente, cuando desde la atalaya de un Tribunal de TFGs llegan a nuestras manos trabajos sobre alguno de estos temas o sobre la política económica del siglo XVIII en España, dirigidos por el homenajeado, no se puede menos que tener en mente la relación que como he dicho se establece inevitablemente en todo buen profesor universitario entre su investigación y su docencia. Por sus aulas han pasado alguno de los profesores y profesoras que en la actualidad conforman el Departamento de Historia Moderna, aquí o en otras universidades: Lluís Torró, Mónica Bolufer, Pablo Pérez, Jorge Catalá o Juan Francisco Pardo.

Pero la docencia de nuestro profesor no concluye, por supuesto, en las sucesivas materias regladas de los múltiples planes de estudio que nos han contemplado desde la década 
de los 70. A lo largo de sus más de cuarenta años como profesor de Historia, Telesforo H. ha desarrollado una consecuente labor de divulgación científica a través de su actividad como conferenciante o participante en cursos y seminarios diversos o cursos de postgrado. No sólo se le ha podido escuchar a propósito de su línea principal de investigación, establecida en torno al tema del capitalismo y ferrocarriles, sino sobre otros muchos que acaban dando cuenta de sus múltiples preocupaciones y de su sentido amplio de la profesión: me refiero a temas como el de la relación entre Inquisición y Humanismo, el del poder en la Edad Moderna en torno a la figura del rey Felipe II, la protoindustrialización valenciana, como ya se ha dicho, o el impacto de la invasión napoléonica en la configuración de los prototipos imaginarios y reales de afrancesados, patriotas y guerrilleros.

Como secretario del comité organizador, formado por los Dres. Pedro Ruiz, Pérez García y Manuel Ardit, participó activamente en la configuración de uno de los primeros cursos de doctorado interdisciplinar e interuniversitario sobre Historia rural. Yo participé como profesora en alguno de estos cursos y tengo que decir que, contemplado con la mirada que proporciona la distancia, no desmerece en absoluto, ni mucho menos, de muchas de las ofertas actualmente impartidas en esta u otras facultades, con la ventaja añadida a su favor de que proporcionaba una auténtica especialización, tanto desde el punto de vista temático como desde el metodológico y técnico. Eran, evidentemente, otros tiempos y otras eran también las preocupaciones del momento y, por tanto, de la Historia.

Destaquemos también su participación en el Master interuniversitario de Historia Moderna, con docencia especialmente en la Universidad de Alicante, con muchos de cuyos profesores del área de Historia Moderna (Giménez, Alberola, etc.) ha establecido una fructífera relación profesional.

Reseñemos finalmente, como conclusión de este apartado, que Telesforo Hernández, tal vez por su poco respeto a los compartimentos estancos de las áreas de investigación y de los Departamentos, ha sabido hacer de ello una virtud al transitar sin ningún tipo de pudor y sí con mucho aprovechamiento intelectual por eso que se llama la interdisciplinariedad, aportando su inevitable perspectiva integradora de historiador a ámbitos tan dispares como la Historia Económica o la Historia del Derecho. Ello da cuenta también de su amplia y creadora visión de la Historia, no sometida a excesivos dogmas o rigideces como no sean aquellos derivados de lo que Marc Bloch denominó en su momento el "oficio de historiador".

\section{ACTIVIDAD INVESTIGADORA}

Cuando yo me trasladé a Valencia, procedente del C.S.I.C. de Madrid, venía con un estudio bajo el brazo en forma de Tesina sobre los gremios de Madrid en siglo XVIII y principios del XIX, es decir, en el tránsito de la Ilustración al Liberalismo. Traía algunas referencias de profesores con quien podía entrevistarme para que me orientasen en la elección de un tema de doctorado. Uno de los primeros, lo recuerdo perfectamente, fue Telesforo Hernández, que en ese momento estaba concluyendo su investigación sobre el tema Ferrocarriles y capitalismo en el País Valenciano: José Campo y la Sociedad de los Ferrocarriles de Almansa a Valencia y Tarragona (1851-1872). A él lo había conocido un tiempo atrás en el Instituto de Madrid "Ramiro de Maeztu", en una de esas frecuentes tanganas que por aquellos años se organizaban contra el sistema de oposiciones a la Enseñanza Media y que 
acabaron con el mecanismo centralizado de las mismas. Reunir a miles y miles de jóvenes en un sólo punto en Madrid a finales de los años 70 demostró ser una bomba de relojería difícilmente digerible por un régimen en sus estertores. La descentralización fue, entonces, no una forma de resolver la articulación territorial y política del país, sino de centrifugar una oposición que, a pesar de su juventud, proporcionaba más de un quebradero de cabeza incluso a los que barruntaban ya una transición más o menos pacífica.

Cuando volví a encontrármelo en Valencia, él había abandonado ya las pretensiones de convertirse en profesor de instituto. Yo lo intentaría años más tarde, aunque también lo abandonaría. Ese fue, como sabemos, el destino de muchos y buenos licenciados a los que las rigideces y el atraso de las estructuras universitarias de entonces impedían una carrera profesional normal en el nivel superior de la enseñanza. En marzo de 1980, Telesforo defendió su tesis doctoral ante un tribunal presidido por Miguel Artola y con Sebastián García Martínez como secretario del mismo y director de la tesis. El resto de vocales fueron Bartolomé Escandell, Josep Fontana y Pere Molas. Dos años más tarde, una parte de ese estudio recibió el XXIV Premio Senyera de Investigaciones Históricas bajo el título de Ferrocarriles y Capitalismo en el País Valenciano.

No insistiré en la paradoja, ya comentada anteriormente, de un tema perteneciente netamente a la edad contemporánea y defendido por un profesor de Historia Moderna. A fin de cuentas, recuerdo muchas tesis doctorales leídas por aquellos años en el Departamento de Historia Contemporánea en las que la mitad de la misma, por no decir sus dos terceras partes, se referían a la sociedad del Antiguo Régimen, no limitada al siglo XVIII, sino incluso arrancando de la crisis del siglo XVII. Quiero advertir que, tal vez por eso, a muchos de nosotros, el famoso decreto regulador del establecimiento de áreas de conocimiento, que delimitó nuestros respectivos rediles de forma tan indeleble, nos pilló ya no con sorpresa, sino con enorme desagrado. Entendíamos en esa época -y Telesforo Hernández lo recordará- de procesos y de problemas históricos, sin que nuestro interés se inquietase ni por un segundo en criterios específicos de tal o cual área. Lo que después vino, todos lo sabemos, fueron criterios también de evaluación específicos para las mismas y, con ello, en algunos casos, el sometimiento de muchos trabajos y trayectorias investigadoras a criterios que debían sancionar a la fuerza, más allá de su calidad o excelencia, la existencia de dichas áreas. Toda una disfunción que muchos han pagado de manera dramática.

Pero no nos engañemos: subyacía en muchos de nosotros en esos momentos, y desde luego Telesforo participaba de esa inquietud, la preocupación por una serie de problemas y de procesos históricos que considerábamos básicos y fundamentales a la hora de definir nuestro País, pensándolo a través de la Historia. El famoso ensayo de Joan Fuster, Nosaltres els valencians, había dejado en el aire una inquietante y sugerente interpretación de cuya riqueza intelectual da cuenta, en cierta manera, la gran cantidad de estudios que directa o indirectamente se dedicaron a contestarla. ¿Era el nuestro el País de una burguesía débil, en concomitancia curiosamente con la teoría de la debilidad de la burguesía española en su conjunto, que no había sabido culminar su peculiar revolución contra el Antiguo Régimen y que había renunciado, por tanto, a un proyecto específico, articulado y cohesionado de País propio, al estilo de la manchesteriana burguesía catalana? ¿Era el nuestro, como mucho, un capitalismo agrario, sobre un mundo rural al que paradójicamente ni se le reconocía muchas veces la gloria de haberse articulado a lo largo de la primera mitad del siglo XIX sobre una auténtica transformación social y jurídica de la propiedad? 
Las respuestas, no siempre coincidentes, a estos y otros interrogantes empezaron a venir desde múltiples disciplinas y desde diversos estudios. A una primera oleada de ellos, de finales de los años 70, que empezaron a lanzar hipótesis y sugerencias a partir de donde las había dejado Fuster o Reglá (Pérez Aparici, García Cárcel, García Martínez, Palop, Clementina Ródenas, Manuel Ardit, etc., etc...) sucedió otra, en la que se inscribe la obra de Telesforo, de los años 80 (Martínez Santos, Ruiz Torres, Garrabou, Millán, etc., etc.) La obra de Telesforo incidía directamente, ya no sobre la articulación del capitalismo, sino la propia existencia de una burguesía empresarial que, en este caso concreto, tenía en la figura del marqués de Campo a uno de sus representantes paradigmáticos. Trabajos posteriores suyos sobre este tema o sobre el más concreto del "Crédito y Banca Privada en el periodo de consolidación del capitalismo en el País Valenciano (1840-1880)" siguieron ampliando y profundizando en el tema.

Esta fue una de sus líneas de investigación preferente, tal vez aquella que mejor define su peculiar aportación a la renovación de la historiografía valenciana de finales de los años 70 y principios de los 80 . Son muchos los trabajos (algo más de 40), que en forma de capítulos de libros dan cuenta de su dedicación al tema, compaginada, como ya se ha dicho, con aportaciones a proyectos relativos a la Historia de las Universidades, concretamente, en la época del Humanismo y la Ilustración. En revistas especializadas ha publicado más de 20 artículos (Hispania, Afers, Saitabi, Estudis o Estudis d'História del País Valencià). Es autor, asimismo, de numerosas voces en diccionarios biográficos e históricos, así como de una quincena aproximada de reseñas de monografías históricas y prólogos a varios libros.

He aludido con anterioridad a aquello que Marc Bloch denomina el "oficio de historiador". Creo que el profesor al que hoy despedimos en este acto ha dado cumplida cuenta a lo largo de su trayectoria de este prototipo. Eso no le ha impedido ni mucho menos, mostrarse siempre atento a las novedades historiográficas, a los cambios metodológicos o a los frecuentes giros historiográficos. Tanto su tema de investigación preferente como sus frecuentes y fecundos contactos con la Universidad de Pau y Manuel Tuñón de Lara le muestran como alguien muy en contacto con ese espacio diseñado a finales de los 70 entre una renovada Historia procedente de Annales, de fuerte componente económico y social, y un marxismo más o menos ortodoxo, del cual nunca, a decir verdad, presumió nuestro profesor. Su dedicación al tema de la protoindustrialización fue su forma peculiar de huir de aquellos aspectos más estructurantes y esterilizantes de aquellas tendencias y su aproximación a modelos de interpretación mucho más complejos y alejados de modelos demasiado esquemáticos. En otras facetas de su investigación, además, ha podido acercarse de manera activa y fructífera a los aspectos de la historia cultural en sentido amplio. Nadie podrá decir de Telesforo Hernández que es un historiador dogmático, de la misma manera que nadie podrá negar que fue, continúa siéndolo, un escrupuloso historiador, incansable buscador y purgador de archivos y de documentos, un apasionado del estudio y de su oficio. Una faceta, además, que ha practicado con un neto sentido de su trascendencia, tanto por lo que hace a la formación de futuras generaciones, como por lo que tiene de aportación a una historia crítica perfectamente incardinada en su entorno social y nacional.

Es difícil despedir a Telesforo Hernández cuando él mismo, en su curriculum, se autoimpone todavía tres líneas de investigación sin cerrar, en fase, como él mismo dice, de recopilación de datos:

1. El primero, relacionado con su proyecto de cátedra, lleva por título "La enseñanza de las humanidades en el siglo XVIII: los seminarios valencianos de nobles", un tema que 
nos puede descubrir el apasionante mundo de la configuración de las elites sociales e intelectuales de esta centuria y su posterior participación en la configuración del nuevo mundo del liberalismo. Y que, con toda seguridad, ahondará en ese apasionante tema histórico que es la relación entre saber y poder en el siglo XVIII.

2. El segundo, en relación con la que ha sido su principal línea de investigación, "La burguesía de negocios en la España liberal del siglo XIX: el marqués de Campo (18141889)". Esperamos, con auténtica impaciencia que el fruto de este proyecto sea la reconstrucción unitaria, a través del método biográfico, de la trayectoria y vicisitudes de un personaje que él conoce tan bien como el marqués de Campo. Será, no lo dudo, un apasionante viaje por todo el siglo XIX no sólo valenciano, sino de España en general.

3. Y el tercero y último, inicialmente en colaboración con nuestro malogrado y añorado Manuel Ardit, "La casa Bertrán de Lis: negocios, política y revolución (1800-1856)”. Telesforo sabe hasta qué punto este tema me interesa. Tuve ocasión de hablar sobre este proyecto cuando todavía vivía el profesor Ardit: con él y con Telesforo proyectamos algún que otro viaje conjunto a archivos londinenses. Lamentablemente, eso sólo lo podré hacer ya con Telesforo. Dado mi interés y preocupación por el político y hacendista José Canga Argüelles, he estado permanentemente en contacto con trabajos y obras, tanto de Manuel Ardit como de Telesforo Hernández, a propósito de esta peculiar y decisiva saga valenciana con quien tuvo contactos y compartió proyectos el político asturiano. ¡Ojalá llegue a buen puerto tan importante proyecto, ahora también asumido por el profesor Germán Ramírez!

A la vista de lo expuesto, convendrán conmigo que resulta muy difícil despedirse de Telesforo Hernández, un constante y excelente profesor, un investigador riguroso y un extraordinario compañero. Tengo la impresión que él se va por imperativo legal y de edad, pero que su intención es la de seguir en la brecha, aunque de otra manera, profundizando en estos o en otros temas, con la seguridad que la mayoría de sus aportaciones seguirán teniendo el rigor y la pasión histórica que han tenido hasta ahora.

En nombre de la Universidad, de la Facultad de Geografía e Historia, de todos sus múltiples discípulos y amigos, muchas felicidades y muchas gracias.

Valencia, 10 de noviembre de 2014

\section{PUBLICACIONES}

\section{A) Libros}

1. T. M. Hernández (1983): Ferrocarriles y capitalismo en el País Valenciano. 1843-1879, 483 páginas. Edita Ayuntamiento de Valencia. Valencia.

\section{B) Capítulo de libros}

1. T. M. Hernández (1975): "Los orígenes de las concesiones ferroviarias en España". En Homenaje al Dr. D. Juan Reglà Campistol. Vol. II, Valencia. Facultad de Filosofía y Letras. Universidad de Valencia, pp. 379-390.

2. T. M. Hernández (1976): "Medidas preventivas del Reino y de la ciudad de Valencia contra la peste de 1628-1631". En Primer Congreso de Historia del País Valenciano. Actas del Congreso celebrado en Valencia los días 14 al 18 de abril de 1971. Vol. III, Valencia. Universidad de Valencia, pp. 379-390. 
3. T. M. Hernández (1978): "Notas para un estudio sobre un tipo específico de sociedades anónimas del siglo XIX: la sociedad del Ferrocarril del Grao de Valencia a Almansa". En Estudios de Historia de Valencia. Valencia, Universidad de Valencia, pp. 399-414.

4. T. M. Hernández (1982): "La economía valenciana en el tránsito del siglo XV al XVI" (Capítulo $2^{\circ}$ ). En VV.AA. Nuestra Historia. Vol. IV. Valencia. Edita Más Ivars-editores, S.L., pp. 25-38.

5. T. M. Hernández (1982): "Los novatores ante la problemática portuaria de Valencia en el siglo XVII". En Estudios dedicados a Juan Peset Aleixandre. Tomo II. Valencia. Universidad de Valencia, pp. 353-374.

6. T. M. Hernández (1983): "La inscripción de censos en Albalat de la Ribera: propuestas para un estudio sobre el crédito privado en el campo valenciano durante el setecientos". En Actes du le colloque sur le Pays Valencien à l'époque moderne. Valencia. Université de Pau (Francia), pp. 283-312.

7. S. Albiñana y T. M. Hernández (1987): "Comentario en torno a la biografía de Tomás Vicente Tosca". En Universidades españolas y americanas. Valencia. Consejo Superior de Investigaciones Científicas y Comisión del V Centenario del descubrimiento de América, pp. 35-55.

8. T. M. Hernández (1988): "La economía valenciana en los años de asentamiento del capitalismo" (Capítulo $1^{\circ}$ ). En VV.AA. Historia del pueblo valenciano. Tomo III. Valencia. Editorial Levante, pp. 665-684.

9. T. M. Hernández, (1989): "La universidad de San Marcos de Lima felicita a las Cortes por la abolición de la Inquisición". En Claustros y Estudiantes. Vol. I. Valencia. Universitat de València, pp. 295-315.

10. T. M. Hernández (1990): "Los afrancesados en la encrucijada de la revolución liberal". En VV.AA. L'impacte de la revolució (1789-1813). València. Generalitat Valenciana. Conselleria de Cultura, Educació i Ciència, pp. 81-96.

11. T. M. Hernández (1990): "Industrial gremial, manufacturas y comerç" (Capítulo III). En VV.AA. Història del País Valencià. L'època borbònica fins a la crisi de l'antic règim. Vol. IV. Barcelona. Edicions 62, pp. 71-109.

12. T. M. Hernández (1991): "Historia de un inmueble municipal: el palau del marqués de Campo, museo de la ciudad". En VV.AA. El marqués de Campo. 100 años después. Valencia. Ajuntament de València, pp. 177-222.

13. T. M. Hernández (1991): "Los negocios ultramarinos del marqués de Campo en Cuba y Filipinas (1880-1886)". En VV.AA. Valencians a Amèrica. Valencia, pp. 131-147. Comisión del V Centenario del descubrimiento de América. Generalitat Valenciana.

14. M. Ardit, V. Gil y T. M. Hernández (1993): "Les français résidents et émigrès dans le pays valencien: les émotions populaires de 1793 et 1794”. En VV.AA. L'Espagne et la France à l'époque de la révolution française (1793-1807). Colloque organisé à Perpignan les 1er, 2 et 3 octobre 1992. Perpignan. Presses Universitaires de Perpignan, Colletion Etudes, pp. 219-246.

15. T. M. Hernández (1996): "Crédito y banca privada en el periodo de consolidación del capitalismo en el País Valenciano (1840-1880)". En J. Azagra, E. Mateu y J. Vidal (Coord.): De la sociedad tradicional a la economía moderna. Alicante. Instituto de Cultura Juan Gil Albert, pp. 196-215.

16. T. M. Hernández (1998): "Jansenismo y Humanismo cristiano en la biblioteca del catedrático-pavorde Mariano Liñán”. En Doctores y escolares. Valencia. Universitat de València, pp. 273-292.

17. T. M. Hernández (1999): "Sociedades ferroviarias, mercado y transporte en el País Valenciano (1844-1914): Nuevos planteamientos”. En M. Muñoz, J. Sanz y J. Vidal Olivares (eds.): Siglo y medio de Ferrocarriles en España. Economía, Sociedad y Cultura. Madrid. Caja de Ahorros del Mediterráneo. Instituto Juan Gil Albert y Fundación de los Ferrocarriles Españoles, pp. 415-431.

18. T. M. Hernández (1999): "Biblioteca de profesores" (Capítulo 20). En. M. Peset (dir.): Historia de la Universidad de Valencia. La Universidad Ilustrada. Vol. II. València. Universitat de València, pp. 117-121.

19. T. M. Hernández (2002): "La Sociedad de los ferrocarriles de Almansa, Valencia y Tarragona: el retorno a la normalidad financiera (1872-1889)" (Capítulo IV). En I. Aguilar y J. Vidal: 150 
años de ferrocarril en la Comunidad Valenciana. 1852-2002. València. Conselleria d'Obres Públiques, Urbanisme i Transports. Generalitat Valenciana, pp. 69-87.

20. T. M. Hernández y V. León Navarro (2003): "El pleito entre la Universidad de Valencia y los jesuitas por las aulas de gramática”. En Aulas y Saberes. Valencia. Universitat de València. Vol. I, pp. 529-540.

21. T. M. Hernández (2004): "La Casa Gabriel Campo e Hijo y la contrata de la recaudación de contribuciones de Valencia (1848-1866)". En Josep Fontana: Història i projecte social. Reconeixement a una trajectòria. Vol 1. Barcelona. Editorial Crítica, pp. 655-666.

22. T. M. Hernández y J. Vidal (2004): "El Ferrocarril de Xàtiva a Alcoy en la Compañía Norte: construcción y explotación, 1888-1920”. En I. Aguilar (coord.): Historia del Ferrocarril en las comarcas valencianas. La Costera. València. Conselleria d'Infraestructures i Transports. Generalitat Valenciana, pp. 167-186.

23. T. M. Hernández (2005): "José Bertrán de Lis (1808-1866)". En J. Vidal (coord.): Cien empresarios valencianos. Madrid, Lid. Editorial empresarial S. L., pp. 44-52.

24. T. M. Hernández (2005): "José Campo Pérez (1814-1889)". En J. Vidal (coord.): Cien empresarios valencianos. Madrid. Lid. Editorial empresarial S.L., pp. 53-64.

25. T. M. Hernández (2006): "Empresarios navieros, movimiento de buques y coyuntura comercial: el puerto del Grao en el Siglo XIX”. En I. Aguilar (coord.): El Comercio y el Mediterráneo. Valencia y la cultura del mar. Valencia. Conselleria d'Infraestructures i Transports. Generalitat Valenciana, pp. 393-417.

26. T. M. Hernández (2006): "Suministradores de tabacos y acaparamiento de contratas: el ejemplo del marqués de Campo, 1860-1887”. En L. Alonso Álvarez, L. Gálvez y S. Luxán (edit.): Tabaco e Historia Económica. Estudios sobre la fiscalidad, consumo y empresa (siglos XVII-XX). Madrid. Fundación Altadis, pp. 335-362.

27. T. M. Hernández (2007): "Diseños y proyectos sobre el puerto de Valencia en los siglos XVII y XVIII". En J. Hermosilla (coord.): Historia del Puerto de Valencia. Valencia. Comisión de la $32^{\mathrm{a}}$ America's Cup. Ministerio de Administraciones Públicas. Universidad de Valencia, pp. 169-184.

28. T. M. Hernández (2007): "Propiedad desamortizada y compensación de créditos: el patrimonio inmobiliario de la familia Bertrán de Lis". En Derecho, historia y universidades. Estudios dedicados a Mariano Peset. València. Universitat de València. Tomo I, pp. 771-780.

29. T. M. Hernández (2007): "Los ramales de prolongación del corredor ferroviario de Castilla la Mancha al Mediterráneo entre 1845 y 1865: rivalidad empresarial y rivalidad comercial". En F. Polo (comp.): Jornadas de Historia Ferroviaria. 150 años de ferrocarril en Albacete (18552005). Albacete. Ayuntamiento de Albacete, pp. 65-90.

30. T. M. Hernández (2007): "Propiedad y gestión. La estrategia empresarial en la Sociedad de los Ferrocarriles de Almansa a Valencia y Tarragona". En I. Aguilar (coord.): Historia del Ferrocarril en las comarcas valencianas. La Plana. Valencia. Conselleria d'Infraestructures i Transports. Generalitat Valenciana, pp. 47-70.

31. V. León y T. M. Hernández (2008): "El plan de estudios de mayores del Seminario Andresiano de Nobles de Valencia". En Ciencia y Academia. IX Congreso Internacional de Historia de las Universidades Hispánicas. Vol I. València. Universitat de València, pp. 529-547.

32. T. M. Hernández (2008): "Los proveedores del ejército y la revolución liberal de 1820: los intereses materiales de Vicente Bertrán de Lis”. En G. Ramírez Aledón (ed.): Valencianos en Cádiz. Joaquín Lorenzo Villanueva y el grupo valenciano en las Cortes de Cádiz. Cádiz. Biblioteca de las Cortes de Cádiz/Ayuntamiento de Cádiz, pp. 349-398.

33. T. M. Hernández y S. Albiñana (2008): "Hacia un sistema general de comunicaciones terrestres en la península ibérica: de los canales de navegación a los caminos de hierro". En R. Franch Benavent y R. Benítez Sánchez-Blanco, Estudios de Historia Moderna en Homenaje a Emilia Salvador Estebán. Vol. II. Economía-Sociedad-Cultura. València. Universitat de València, pp. 637-660. 
34. T. M. Hernández: "Las manufacturas textiles valencianas en los siglos XVI al XIX; un estado de la cuestión". Ontinyent. Museo Textil de la Comunitat Valenciana. En prensa.

35. T. M. Hernández (2009): "La política económica del reformismo borbónico y el auge de las manufacturas valencianas en el siglo XVIII". En Ricardo Franch (dir.): La sociedad valenciana tras la abolición de los fueros. València. Institució Alfons el Magnànim, pp. 403-439.

36. T. M. Hernández (2009): "La Real Sociedad Económica de Amigos del País". En VV.AA.: La ciudad de Valencia. Historia, Geografía y Arte de la ciudad de Valencia. Vol. $1^{\circ}$. Valencia, pp. 310-313.

37. T. M. Hernández (2009): "La Educación elemental y secundaria en la ciudad de Valencia en el siglo XVIII". En VV.AA. La ciudad de Valencia. Historia, Geografía y Arte de la ciudad de Valencia. Vol. $1^{\circ}$. Valencia, pp. 400-405.

38. T. M. Hernández (2010): "El apoyo de la Sociedad Económica de Amigos del País a las empresas promovidas por José Campo (1840-1855)". En N. Bas y M. Portolés (coords.): Ilustración y progreso: la Real Sociedad Económica de Amigos del País de Valencia (1776-2009). Valencia, pp. 201-245.

39. V. León y T. M. Hernández (2010): "La reforma de la Universidad Valenciana en la correspondencia de Gregorio Mayans". X Congreso de Historia de las Universidades Hispánicas. Facultades y Grados. Vol. 1. Valencia, pp. 481-502.

40. V. León y T. M. Hernández (2012): "Educación pública, patria y religión en el tránsito del siglo XVIII al XIX”. Matrícula y Lecciones. XI Congreso Internacional de Historia de las universidades hispánicas (Valencia, 2 al 5 de noviembre de 2011). Universitat de València, pp. 483-502.

41. T. M. Hernández y J. Vidal (2012): "De la opción litoral al corredor mediterráneo: los ferrocarriles de Almansa a Valencia y Tarragona". I. Aguilar (coord.): Historia del Ferrocarril en las Comarcas Valencianas. El Camp de Morvedre. Generalitat Valenciana. Conselleria d'Infraestructures, Territori i Medi Ambient. Valencia, pp. 39-56.

42. T. M. Hernández: "Las dos etapas en la trayectoria vital del marqués de Campo". En Bicentenario del nacimiento del marqués de Campo. En prensa.

\section{C) Artículos en revistas especializadas}

1. T. M. Hernández (1975): "La etapa especulativa del ferrocarril español. Un ejemplo práctico: el Madrid and Valencia Railway, 1845-1849”. En Estudis, 4. Valencia, pp. 255-275.

2. T. M. Hernández y J. Piqueras (1980): "Materiales para la historia de los precios en Valencia durante el siglo XIX”. En Estudis, 7. Valencia, pp. 155-215.

3. T. M. Hernández (1980): "Diez consideraciones en torno a la construcción de los ferrocarriles de vía ancha y el papel de un empresario histórico: Jose Campo". En Estudis d'història contemporanea del País Valencià, 2. València, pp. 435-449.

4. S. Albiñana y T. M. Hernández (1983): "Notas sobre técnica y proyectismo en la Albufera y el Júcar en la edad moderna". Estudis, 10. Valencia, pp. 55-90.

5. S. Albiñana y T. M. Hernández (1984): “Técnica e ilustración en Valencia: los proyectos portuarios”. En Saitabi, 34, Valencia, pp. 125-151.

6. T. M. Hernández (1985): "La historia integral y el País Valenciano". En Saò, 82. València, pp. 15-18.

7. T. M. Hernández (1987): "Els novators i els mestres d'obra de València (1675-1740)". En Afers, 5/6. Catarroja-València, pp. 421-465.

8. T. M. Hernández y J. Vidal (1991): "Infraestructura viaria y ferrocarriles en la articulación del espacio económico valenciano. 1750-1914". Hispania, 177. Madrid, pp. 205-243.

9. T. M. Hernández (1992): "Los acreedores censalistas de propios y la burguesía liberal”. En Saitabi, 42. Valencia, pp. 47-62.

10. T. M. Hernández (1992): "Tabacs, vapors i finances: el marqués de Campo i les colònies hispano-americanas al segle XIX”. Monográfico sobre València i Amèrica. En Saó, monogràfics, II. Valencia, pp. 30-33. 
11. T. M. Hernández (1993): "Tensions familiars i patrimoni: ventura i desventura de la fortuna acumulada pel marqués de Campo". Afers, 16. Catarroja-València, pp. 374-376.

12. T. M. Hernández (1994): "Negocis i ferrocarrils: el perfil dels concessionaris (1845-1855)". L'Avenç, 180. Barcelona, pp. 12-17.

13. M. Peset y T. M. Hernández (1994): "De la Justa expulsión de los moriscos de España”. Estudis, 20. Valencia, pp. 231-252.

14. T. M. Hernández (1997): "Enseñanza de latinidad y humanidades en la renovación pedagógica del Seminario Andresiano de Nobles (1763-1785)". Estudis, 23. Valencia, pp. 269-296.

15. T. M. Hernández y V. León Navarro (1998): "La pugna entre jesuitas y escolapios en Valencia por el control de la enseñanza secundaria (1737-1760)". Estudis, 24. Valencia, pp. 307-337.

16. V. León Navarro y T. M. Hernández (2002): "El Real Seminario de Nobles Educandos de Valencia (1767-1784). ¿Un símbolo del reformismo educativo?”. Anales Valentinos, 55. Valencia, pp. $129-153$.

17. T. M. Hernández y V. León Navarro (2003): "La defensa de la Universidad de Valencia en 1741. ¿Antijesuitismo o corporativismo académico?”. Estudis, 28. Valencia, pp. 317-343.

18. T. M. Hernández (2003): "Acotaciones a los archivos de la ciudad de Valencia. Notas críticas". En Anales (Real Sociedad Económica de Amigos del País), 2001-2002. Vol. II, Valencia, pp. 643-652.

19. T. M. Hernández y A. Yanini (2003): "Les primeres passes del silvelisme valencià. El paper mediador de Pasqual Dasí i Puigmoltó, vescomte de Bétera (1876-1880)". En Afers, 46, pp. 693-714.

20. T. M. Hernández (2006): "Contratas y contratistas de tabacos rama en España: el caso paradigmático del marqués de Campo (1860-1887)". Revista de Historia. Transportes, Servicios y Telecomunicaciones, $\mathrm{n}^{\mathrm{o}}$ 11. Madrid, pp. 40-69 (Versión actualizada del estudio presentado en el punto 26 del apartado Capítulo de libros).

21. T. M. Hernández (2011): "La educación patriótica en el Seminario Andresiano de las Escuelas Pías: el certamen de la Academia literaria de 1767". Estudis, 37. Valencia, pp. 325-345.

22. T. M. Hernández (2012): "Sebastià García Martínez i el Col·legi Major Lluís Vives". Afers. 73, pp. 767-790.

23. T. M. Hernández (2013): "Manuel Ardit i la història creativa". Saitabi, 62-63, pp. 343-359.

\section{D) Artículos en diccionarios y enciclopedias}

T. M. Hernández (1991):

1 Voz de "Jose Campo, marqués de Campo". Tomo 4, p. 228.

2 Voz de "Ferrocarriles". Tomo 4, pp. 250-251.

3 Voz de "Protoindustria". Tomo 7, pp. 280-283.

En Gran Enciclopedia Valenciana. Edita Difusora de Cultura Valenciana (Tabarca). Valencia.

T. M. Hernández (1993):

4 Voz de "Familia Bertrán de Lis". Tomo 1, pp. 143-144.

5 Voz de "Sublevación de Boné". Tomo 1, p. 154.

6 Voz de "José Campo, marqués de Campo". Tomo 1, pp. 183-184.

7 Voz de "Exposición regional valenciana". Tomo 1, p. 352.

8 Voz de "Ferrocarril". Tomo 1, pp. 374-375.

9 Voz de "Familia Galiano, marqueses de Montortal". Tomo 1, pp. 397-398.

10 Voz de "Mayans y Enríquez de Navarra, Luis". Tomo 2, pp. 517-518.

En Diccionario Histórico de la Comunidad Valenciana. Valencia. Editorial Levante.

T. M. Hernández (1995):

11 Voz de "Ferrocarril", pp. 294-299.

En M. Cerdá y M. García Bonafé (dirs.): Enciclopedia Valenciana de Arqueología Industrial. València. Edicions Alfons el Magnànim. Generalitat Valenciana-Diputació Provincial de Valencia. 
T. M. Hernández (2003):

12 "Vicent Genovès i Amorós" (Historiador valenciano).

A. Simón (dir.): Diccionari d'Historiografia Catalana. Barcelona. Enciclopedia Catalana, p. 455.

13 T. M. Hernández y V. León Navarro (1999): "La Enseñanza primaria y secundaria". En A. Furió (dir.): Capítulo 31. El Siglo de los Ilustrados, pp. 376-377. Historia de Valencia. Valencia. Editorial Prensa Valenciana S.A. Levante. El Mercantil Valenciano.

14 T. M. Hernández (1999): "Los orígenes de la banca valenciana", pp. 453-455. Ibidem.

15 T. M. Hernández (1999): "El marqués de Campo", pp. 454-455. Ibidem.

16 T. M. Hernández (1999): "El impacto del ferrocarril”, pp. 456-457. En A. Furió (dir.): Capítulo 38. El Triunfo del Capital. Historia de Valencia. Valencia. Editorial Prensa Valenciana S.A. Levante-El Mercantil Valenciano. 